\title{
Metagenomic Analysis Exploring Taxonomic and Functional Diversity of Soil Microbial Communities in Sugarcane Fields Applied with Organic Fertilizer
}

\author{
Ruoyu Li, ${ }^{1,2,3}$ Ziqin Pang, ${ }^{1,2,4}$ Yongmei Zhou, ${ }^{2,3}$ Nyumah Fallah, ${ }^{2}$ Chaohua Hu, ${ }^{1}$ \\ Wenxiong Lin, ${ }^{2}$ and Zhaonian Yuan (i) ${ }^{1,4}$ \\ ${ }^{1}$ Key Laboratory of Sugarcane Biology and Genetic Breeding, Ministry of Agriculture, Fujian Agriculture and Forestry University, \\ Fuzhou 350002, China \\ ${ }^{2}$ College of Agricultural, Fujian Agriculture and Forestry University, Fuzhou 350002, China \\ ${ }^{3}$ Genomics and Biotechnology, Fujian Agriculture and Forestry University, Fuzhou 350002, China \\ ${ }^{4}$ Province and Ministry Co-Sponsored Collaborative Innovation Center of Sugar Industry, Guangxi University, \\ Nanning 530000, China
}

Correspondence should be addressed to Zhaonian Yuan; yuanzn05@163.com

Received 18 May 2020; Revised 22 September 2020; Accepted 25 September 2020; Published 21 October 2020

Academic Editor: Alfieri Pollice

Copyright $\odot 2020$ Ruoyu Li et al. This is an open access article distributed under the Creative Commons Attribution License, which permits unrestricted use, distribution, and reproduction in any medium, provided the original work is properly cited.

\begin{abstract}
Organic fertilizers are critically important to soil fertility, microbial communities, and sustainable agricultural strategies. We compared the effect of two fertilizer groups (organic+chemical fertilizer: OM, chemical fertilizer: CK) on sugarcane growth, by observing the difference in microbial communities and functions, soil nutrient status, and agronomic characters of sugarcane. The results showed that the sugar content and yield of sugarcane increased significantly under organic fertilizer treatment. We believe that the increased soil nutrient status and soil microorganisms are the reasons for this phenomenon. In addition, redundancy analysis (RDA) shows that the soil nutrient condition has a major impact on the soil microbial community. In comparison with CK, the species richness of Acidobacteria, Proteobacteria, Chloroflexi, and Gemmatimonadetes as well as the functional abundance of nucleotide metabolism and energy metabolism increased significantly in the OM field. Moreover, compared with CK, genes related to the absorption and biosynthesis of sulfate were more prominent in OM. Therefore, consecutive organic fertilizer application could be an effective method in reference to sustainable production of sugarcane.
\end{abstract}

\section{Introduction}

Sugarcane (Saccharum officinarum L.; Poaceae) is the world's most important sugar and energy crop. Sugarcane plants are very tall, have a long production period, consume a lot of nutrients, and require a large amount of fertilizer as well as large amount of irrigation [1-3]. Balanced soil fertility plays a vital role in the growth of sugarcane. However, extensive use of chemical fertilizers severely depletes the nutrients in the soil, which will significantly reduce the yield of cultivated land [4]. Studies have shown that the application of organic fertilizer enhanced soil porosity, improved the soil aggregate structure, and adjusted various physical and chemical properties [4]. It is generally believed that a higher soil microbial diversity index is more conducive to improving the stability and resistance of soil ecosystems, ensuring normal operation of soil ecosystem function [5]. Organic fertilizers such as straw returning and pig manure contain a large number of microorganisms, and studies have shown that the nutrient matrix provided by the application of organic fertilizer eased competition among bacterial groups [6]. On the other hand, organic fertilizer itself contains a large number of microorganisms, substantially improving soil bacterial diversity [7]. The species and quantity of soil microorganisms not only are dynamic for the transformation and circulation of soil organic matter and soil nutrients but also act as reserve storage for the available nutrient of plants in the soil and are closely coupled with soil fertility. Soil may contain massive 
numbers of microbial species, such as fungi, viruses, bacteria, and archaea [8]. The majority of these taxa have not been described in detail and have unknown physiological and ecological attributes [9].

The concept of metagenomics was formally defined by Jo Handelsman of the University of Wisconsin. Metagenomics is a popular method of microbial research that uses highthroughput sequencing technology to characterize the taxonomic and functional attributes of biological communities [10]. Metagenomics avoids the separation of organisms and directly detects and quantifies DNA. It can quickly and accurately obtain abundant microbial data and has been widely used in the research of soil microorganisms [11-13]. Metagenomics has also been used in many sugarcane soil-related research projects. Studies have shown that no-tillage and bagasse mulching can affect the types and functions of soil microorganisms, and the impact on microbial function is less than that on community composition [14]. These functional changes may affect the productivity of sugarcane. Metagenomics has also been applied to detect sugarcane diseases. Studies have found that Sugarcane Yellow Canopy Syndrome is related to the function of specific soil microorganisms [15]. In addition, metagenomics has also found that earthworms can change the functional classification of soil microorganisms in a sugarcane field by increasing the accumulation of sugarcane biomass [16]. However, there are few reports on the relationship among the growth of sugarcane, the soil nutrients, and the changes of soil microorganisms under application of organic fertilizers. Thus, the objective of this study is to explore the effects of organic fertilizer on sugarcane growth, soil nutrients, and variation in the taxonomic composition of soil microbial communities.

\section{Materials and Methods}

2.1. Experimental Design and Sample Collection. The experimental field is situated in the Sugarcane Experimental Base $\left(26^{\circ} 08^{\prime} \mathrm{N}, 119^{\circ} 23^{\prime} \mathrm{E}\right)$ of Fujian Agriculture and Forestry University, China. The area belongs to the subtropical monsoon climate region. The average annual temperature is $20^{\circ} \mathrm{C}$, and the annual mean precipitation is $1363.91 \mathrm{~mm}$. The soil was classified as yellow soil, and the maximum water holding capacity was $33.5 \%$. Soil $\mathrm{pH}$ (5.21), soil organic matter $\left(19.59 \mathrm{~g} \mathrm{~kg}^{-1}\right)$, available phosphorus $(16.1 \mathrm{mg} / \mathrm{kg})$, and available potassium $(89.47 \mathrm{mg} / \mathrm{kg})$ were measured before the experiment. The sugarcane variety ROC22 [17] was selected as the experimental crop and planted in March 2012 at a seeding rate of about 100,000 double shoots $/ \mathrm{hm}^{2}$ $\left(1 \mathrm{hm}^{2}=10000 \mathrm{~m}^{2}\right)$.

We used a randomized block design of two treatments: (1) conventional fertilization (CK), in which $300 \mathrm{~kg} / \mathrm{hm}^{2}$ urea, $100 \mathrm{~kg} / \mathrm{hm}^{2} \mathrm{~K}_{2} \mathrm{O}$, and $400 \mathrm{~kg} / \mathrm{hm}^{2}$ superphosphate were applied, and (2) chemical fertilizer combined with organic fertilizer (OM), in which $225 \mathrm{~kg} / \mathrm{hm}^{2}$ urea, $75 \mathrm{~kg} / \mathrm{hm}^{2}$ urea, $300 \mathrm{~kg} / \mathrm{hm}^{2}$ superphosphate, and $1125 \mathrm{~kg} / \mathrm{hm}^{2}$ organic fertilizer (organic content $>45 \%$ ) were applied (Table 1). Each treatment consisted of 3 plots, with each plot containing 3 rows. The row spacing was $1.2 \mathrm{~m}$, the row length was $8.0 \mathrm{~m}$, and the total plot area was $28.8 \mathrm{~m}^{2} .40 \%$ and $60 \%$ of the total fertilization amount was applied to the sugarcane at the seedling stage and the elongation stage, respectively. On March 8, 2019 , soil samples were collected at the depth of approximately $10 \mathrm{~cm}$ of the topsoil; all soil samples were taken no less than two inches away from a plant stalk. Each soil sample was fully mixed to filter out impurities such as plant roots. A portion of each sample was air-dried to analyze physical and chemical properties of the soil, while the rest were stored at $-80^{\circ} \mathrm{C}$ for DNA extraction. Sugarcanes were harvested on March 10, 2019, and each harvested plant was used to measure plant height, stem diameter, stem weight, hammer weight, and other indicators.

2.2. Measurement of Sucrose Content and Theoretical Yield. We measured the stalk height and diameter of 30 sugarcane plants that were randomly selected in each plot using a measuring tape and a Vernier caliper. In order to get the sucrose content, an Extech Portable Sucrose Brix Refractometer (Mid-State Instruments, CA, USA) was applied to measure the samples with the following formula [18]:

$$
\operatorname{sucrose}(\%)=\operatorname{brix}(\%) \times 1.0825-7.703
$$

For the estimation of theoretical production of sugarcane, these equations were followed: (1) Single stalk weight $(\mathrm{kg})=$ $[\text { stalk diameter }(\mathrm{cm})]^{2} \times[$ stalk height $(\mathrm{cm})-30] \times 1\left(\mathrm{~g} / \mathrm{cm}^{3}\right)$ $\times 0.7854 / 1000$ and (2) Theoretical production $\left(\mathrm{kg} / \mathrm{hm}^{2}\right)=$ single stalk weight $(\mathrm{kg}) \times$ productive stem numbers $\left(\mathrm{hm}^{2}\right)$.

2.3. Measurement of Soil Chemical Properties. The $\mathrm{pH}$ meter PHS-3C (INESA Scientific Instrument Co., Ltd., Shanghai, China) was used to estimate the soil pH [19]. Elemental analyzers (Thermo Scientific ${ }^{\mathrm{TM}}$, Waltham, MA, USA) were used to measure total soil sulfur (TS), total carbon (TC), and total nitrogen (TN) in extracts. Effective phosphorus (AP) was measured using hydrochloric acid and ammonium fluoride following the molybdenum blue protocol [20]. The alkaline hydrolyzable diffusion and potassium dichromate external heating methods were used to measure available nitrogen (AN) and organic matter $(\mathrm{OM})$, respectively $[21,22]$. We used ammonium acetate to extract available potassium (AK) and measured it by flame photometry [23]. Total potassium (TK) and total phosphorus (TP) were measured by first digesting the soil by adopting the $\mathrm{H}_{2} \mathrm{SO}_{4}-\mathrm{HCLO}_{4}$ method and then calculating the level as defined for AP and AK.

2.4. Soil DNA Extraction and Metagenomic Sequencing. Soil DNA was extracted using the E.Z.N.A. ${ }^{\circledR}$ DNA Kit (Omega Bio-Tek, Norcross, GA, U.S.) according to the manufacturer's instructions. Quality and concentration of extracted DNA were assayed with NanoDrop 2000.

The extracted DNA was fragmented into a size of approximately 300 bp with Covaris M220 (Gene Company Limited, China), and the TruSeq ${ }^{\mathrm{TM}}$ DNA Sample Prep Kit (Illumina, San Diego, CA, USA) was used to construct the paired-end library. Blunt-end fragments were ligated with adapters containing the full complement of sequencing primer hybridization sites. Paired-end sequencing was performed using the HiSeq 3000/4000 PE Cluster Kit and HiSeq 3000/4000 SBS 
TABLE 1: Soil management and fertilizer regimes every year.

\begin{tabular}{lc}
\hline Sugarcane fields & Soil fertilizer regimes \\
\hline $\mathrm{CK}$ & $\begin{array}{c}\text { Fertilization with potassium oxide }\left(100 \mathrm{~kg} / \mathrm{hm}^{2}\right), \text { calcium superphosphate fertilizer }\left(400 \mathrm{~kg} / \mathrm{hm} \mathrm{m}^{2}\right), \\
\text { and urea }\left(300 \mathrm{~kg} / \mathrm{hm}^{2}\right) \text { in April every year. }\end{array}$ \\
$\begin{array}{c}\text { Fertilization with potassium oxide }\left(75 \mathrm{~kg} / \mathrm{hm}^{2}\right), \text { calcium superphosphate fertilizer }\left(300 \mathrm{~kg} / \mathrm{hm}{ }^{2}\right), \\
\text { and urea }\left(225 \mathrm{~kg} / \mathrm{hm}^{2}\right) \text { in April every year. }\end{array}$ \\
$\begin{array}{c}\text { Fertilization with organic fertilizer }\left(1125 \mathrm{~kg} / \mathrm{hm}^{2}\right)\left(26.4 \% \text { organic C, } 2.5 \% \text { total N, } 1.6 \% \mathrm{P}_{2} \mathrm{O}_{5},\right. \\
\text { and } 1.3 \% \mathrm{~K}_{2} \mathrm{O}, \text { made of composted rice straw and pig manure by Tianniang Ltd. of Changshu, China) } \\
\text { in April every year. }\end{array}$
\end{tabular}

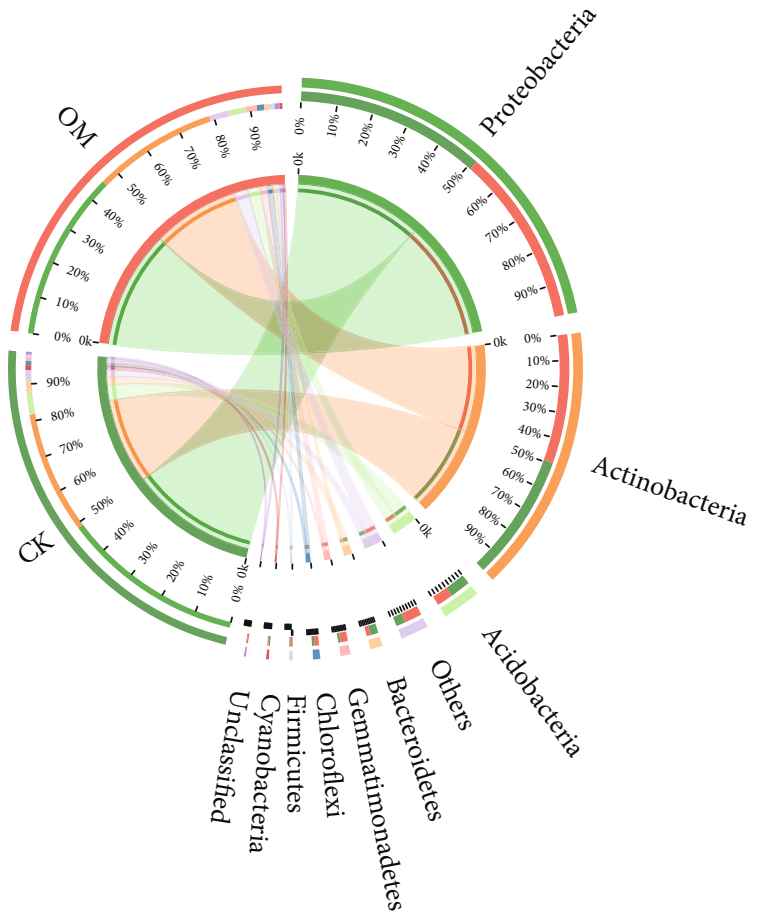

(a)

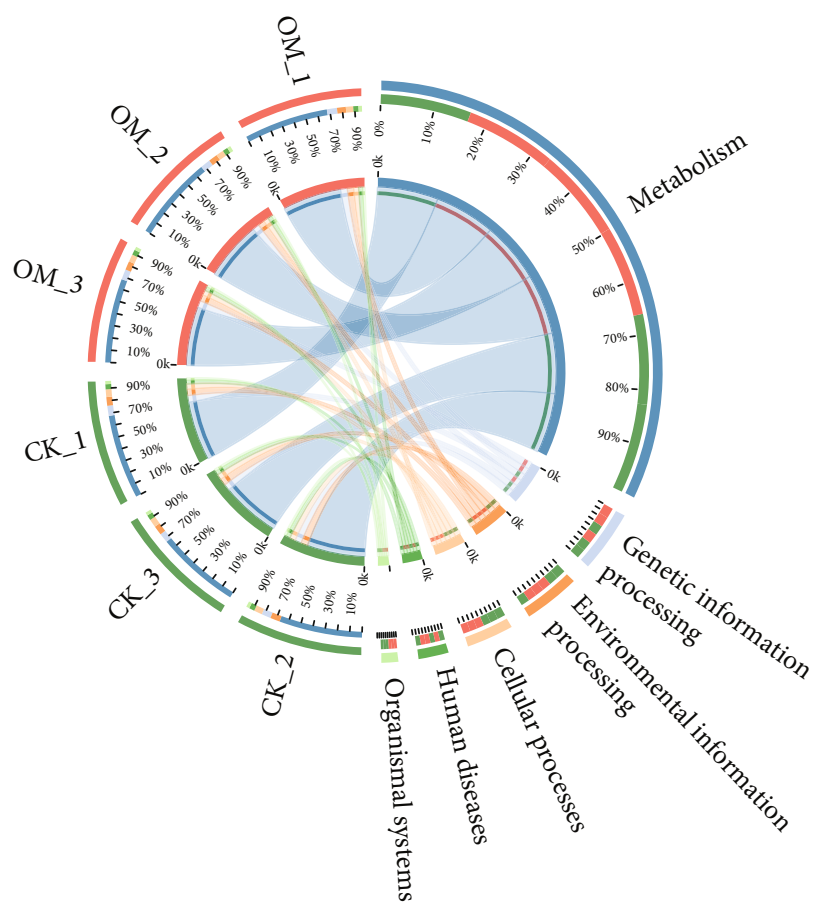

(b)

Figure 1: Circos diagram represents the microbial composition (a) and functional composition (b) of top phyla in two sugarcane fields.

Kit according to the manufacturer's instructions at Majorbio Bio-Pharm Technology Co., Ltd. (Shanghai, China).

2.5. Bioinformatics. SeqPrep V. 1.3.2 (https://github.com/ jstjohn/SeqPrep) was used to strip adapter sequences. We used Sickle v. 1.33 (https://github.com/najoshi/sickle) to remove the low-quality reads (length $<50 \mathrm{bp}$ or with a quality value $<20$ or having $\mathrm{N}$ (ambiguity) bases). Metagenomic data were assembled using MEGAHIT v. 1.1.2 [24], and open reading frames (ORFs) of contigs in stitching results were predicted using MetaGene v. 2.20.0 [25]. The predicted ORFs with lengths over $100 \mathrm{bp}$ were retrieved and translated into protein sequences using the NCBI translation table. CD-HIT v. 4.6.8 was used to cluster the predicted genes, and a nonredundant gene catalog was constructed using the longest sequences from each cluster [26]. Reads after quality control were mapped against the representative sequences using SOAPaligner v. 2.21 (R. [27]). Next,
BLASTP v. 2.2.28+ [28] was used to align nonredundant gene sets to the NCBI NR database [29] for taxonomic annotation. BLASTP was also used for the Kyoto Encyclopedia of Genes and Genomes (KEGG) annotation [30]. The aligned sequence data were fed to KOBAS v. 2.0 for functional annotation at the three levels of L1, L2, and L3 [31]. Based on the annotation results, Circos v. 0.67-7 [32] was used to present the corresponding components of microorganisms and KEGG functional annotation in two groups (Figure 1). Differences in microbial taxa between OM and CK were calculated and visualized using linear discriminant analysis effect size (LEfSe), and LDA scores exceeding 3.5 were confirmed by LEfSe [33]. R v. 3.5.1 (https://www.r-project.org/) was used for PCoA analysis and mapping. PCoA analysis was performed to find the most essential elements and structures in the data. Analysis of similarities (ANOSIM) was used to test whether the difference between groups was significantly greater than that within groups, so as to judge whether 
grouping was meaningful. Redundancy analysis (RDA) was executed in $\mathrm{R}$ to analyze the relationship between dominant taxa of microorganisms and soil properties.

\section{Results}

3.1. Soil Physiochemical Properties. The results showed that the application of organic fertilizers affected sugarcane physicochemical properties. The $\mathrm{pH}$ of the soil increased significantly $(p<0.05)$, which effectively relieved the acidification of the soil. Furthermore, soil organic matter content increased significantly, with an increase amplitude of $98.0 \%$ $(p<0.05)$. Soil TS contents of the OM treatment were significantly lower compared to the CK treatment $(p<0.05)$. Soil TN, TP, C_N, AN, and AP increased slightly after applying organic fertilizer, but the increases were not significant (Table 2).

3.2. Sugarcane Agronomic Properties and Production. The results revealed that the application of organic fertilizers affected some sugarcane agronomic parameters significantly. The brix of sugarcane increased from $8.17 \%$ to $11.16 \%$, with an increase amplitude of $36.6 \%(p<0.05)$. The production of sugarcane increased from $38,920.82 \mathrm{~kg} / \mathrm{hm}^{2}$ to $54,367.45 \mathrm{~kg} / \mathrm{hm}^{2}$, with an increase amplitude of $39.7 \%$. The stalk height, stalk diameter, and productive stem numbers of sugarcane increased slightly, but the increase amplitude was not significant (Table 3).

3.3. Principal Coordinate Analysis (PCoA) of Soil Microorganisms. We found that the composition and function of the rhizosphere soil microbiota differed with respect to fertilizer regime. Unconstrained principal coordinate analysis (PCoA) of Bray-Curtis distances revealed that the rhizosphere microbiota of both OM and CK treatments formed two distinct clusters, which separated along the first coordinate axis. The principal coordinate axis 1 (PC1) and the principal coordinate axis 2 (PC2) can be used to interpret $68.51 \%$ and $17.54 \%$ of the variation in taxonomic classification (Figure $2(\mathrm{a})$ ) and $98.61 \%$ and $0.81 \%$ in functional capacity (Figure 2(b)). The cumulative variance contribution rates of the two principal components reached $86.05 \%$ and $99.42 \%$ in classification and function, respectively, which can separate the two groups based on their specific characteristics. The ANOSIM analysis confirmed that the soil microbial composition and function were significantly different under $\mathrm{OM}$ and CK treatments $(p<0.05)$. Therefore, on the foundation of applying chemical fertilizer, we can conclude that organic fertilizer is the main factor affecting the taxonomic composition and function of soil microbial communities. In addition, the correlation analysis of the principal component coordinate axis of microbial species exhibits a significant linear relationship between community composition and function (Figure 2(c), $R^{2}=0.955, p<0.01$ ).

3.4. Microbial Community Analysis. A total of 13,101 microorganism species were detected in the OM treatment, of which bacteria accounted for $98.61 \%$ and other microorganisms accounted for $1.39 \%$. In the CK treatment, 13,720 species were detected and the proportion of bacteria and other microorganisms were $99.24 \%$ and $0.76 \%$, respectively. In
TABLE 2: Impact of organic fertilizer application on soil physiochemical properties of sugarcane.

\begin{tabular}{lcc}
\hline Specimen name & CK & OM \\
\hline pH & $4.78 \pm 0.23^{\mathrm{b}}$ & $6.48 \pm 0.12^{\mathrm{a}}$ \\
OM & $15.42 \pm 4.43^{\mathrm{b}}$ & $30.53 \pm 6.15^{\mathrm{a}}$ \\
$\mathrm{TN}$ & $0.90 \pm 0.21^{\mathrm{a}}$ & $1.24 \pm 0.41^{\mathrm{a}}$ \\
$\mathrm{TP}$ & $0.54 \pm 0.18^{\mathrm{a}}$ & $0.79 \pm 0.09^{\mathrm{a}}$ \\
TK & $23.57 \pm 1.45^{\mathrm{a}}$ & $25.38 \pm 0.42^{\mathrm{a}}$ \\
TS & $0.21 \pm 0.03^{\mathrm{a}}$ & $0.12 \pm 0.02^{\mathrm{b}}$ \\
$\mathrm{C} \_\mathrm{N}$ & $18.10 \pm 8.20^{\mathrm{a}}$ & $26.34 \pm 10.58^{\mathrm{a}}$ \\
AN & $67.78 \pm 9.67^{\mathrm{a}}$ & $70.10 \pm 2.79^{\mathrm{a}}$ \\
AK & $78.36 \pm 8.95^{\mathrm{a}}$ & $89.60 \pm 7.54^{\mathrm{a}}$ \\
AP & $15.38 \pm 5.80^{\mathrm{a}}$ & $14.89 \pm 1.76^{\mathrm{a}}$ \\
\hline
\end{tabular}

aAll values are the mean of three replicates. Numbers followed by " \pm " represent the standard errors. ${ }^{\mathrm{b}}$ The data with identical superscript letters indicate that the mean values are not significantly different.

TABLE 3: Impact of organic fertilizer application on sucrose content, growth parameters, and yield of sugarcane.

\begin{tabular}{lcc}
\hline Treatment & CK & OM \\
\hline Stalk height $(\mathrm{cm})$ & $236.67 \pm 15.28^{\mathrm{a}}$ & $258.67 \pm 10.26^{\mathrm{a}}$ \\
Stalk diameter $(\mathrm{cm})$ & $1.63 \pm 0.07^{\mathrm{a}}$ & $1.81 \pm 0.12^{\mathrm{a}}$ \\
Sucrose content $(\%)$ & $8.17 \pm 1.47^{\mathrm{b}}$ & $11.16 \pm 0.37^{\mathrm{a}}$ \\
Available stalk number $\left(\mathrm{hm}^{-2}\right)$ & $89,556 \pm 4,018^{\mathrm{a}}$ & $92,000 \pm 8,664^{\mathrm{a}}$ \\
Production $\left(\mathrm{kg} / \mathrm{hm}^{2}\right)$ & $38,921 \pm 5,592^{\mathrm{b}}$ & $54,367 \pm 6,143^{\mathrm{a}}$ \\
\hline${ }^{\mathrm{a}}$ All values are the mean of three replicates. Numbers followed by “ $\pm ”$ \\
represent the standard errors. ${ }^{\mathrm{b}}$ The data with identical superscript letters \\
indicate that the mean values are not significantly different.
\end{tabular}

both fields, the top dominant microorganism phyla were identified, namely, Proteobacteria, Actinobacteria, Bacteroidetes, Gemmatimonadetes, Chloroflexi, Firmicutes, and Cyanobacteria (Figure 1(a)). The dominant phyla in the microbial communities showed great differences between the two fields. The OM field was significantly enriched with Acidobacteria, Proteobacteria, Chloroflexi, and Gemmatimonadetes compared with the CK field. However, at the genus level, the OM field was more enriched with Pyrinomonas, Solirubrobacter, Arthrobacter, Nocardia, Gemmatimonas, Polaromonas, and Caulobacter than the CK field (Figure 3(a)).

3.5. Relationship between Microbial Community Structure and Environmental Characteristics. Redundancy analysis (RDA) was used to assess the environmental factors influencing the microbial structure. The results revealed that the microbial community structure was affected by primary environmental characteristics. The RDA results suggested that soil $\mathrm{pH}, \mathrm{OM}, \mathrm{TN}, \mathrm{TP}$, and TS accounted for $91.71 \%$ of the total shift in microbial communities (Figure 4). The OM samples were completely separated from the CK samples. Bradyrhizobium, Sphingomonas, Massilia, Mycobacterium, Streptomyces, and Burkholderia were positively associated with TS but negatively correlated with TN, TP, OM, and $\mathrm{pH}$. In addition, Solirubrobacter, Arthrobacter, and Nocardioides were positively 


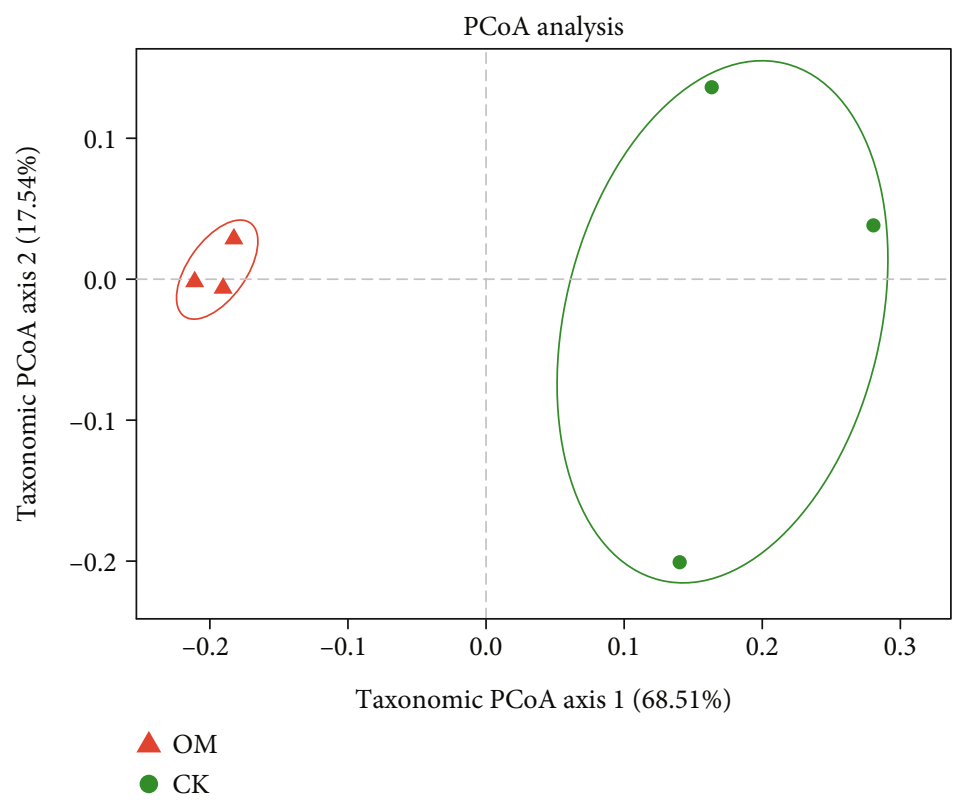

(a)

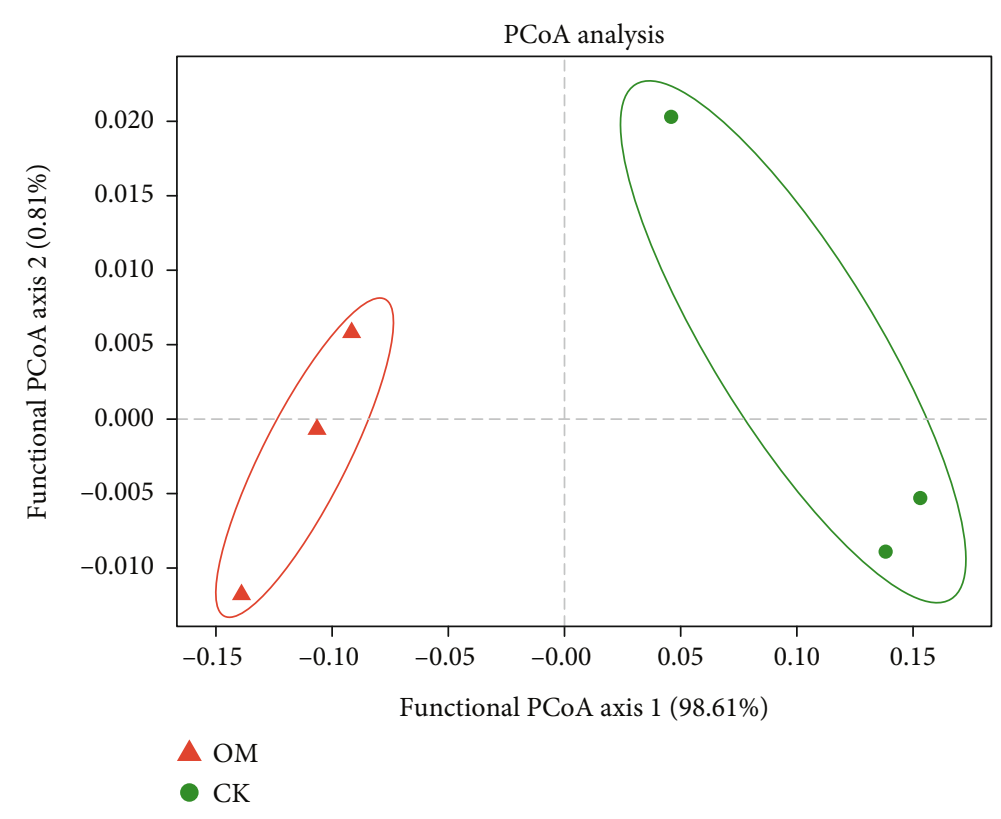

(b)

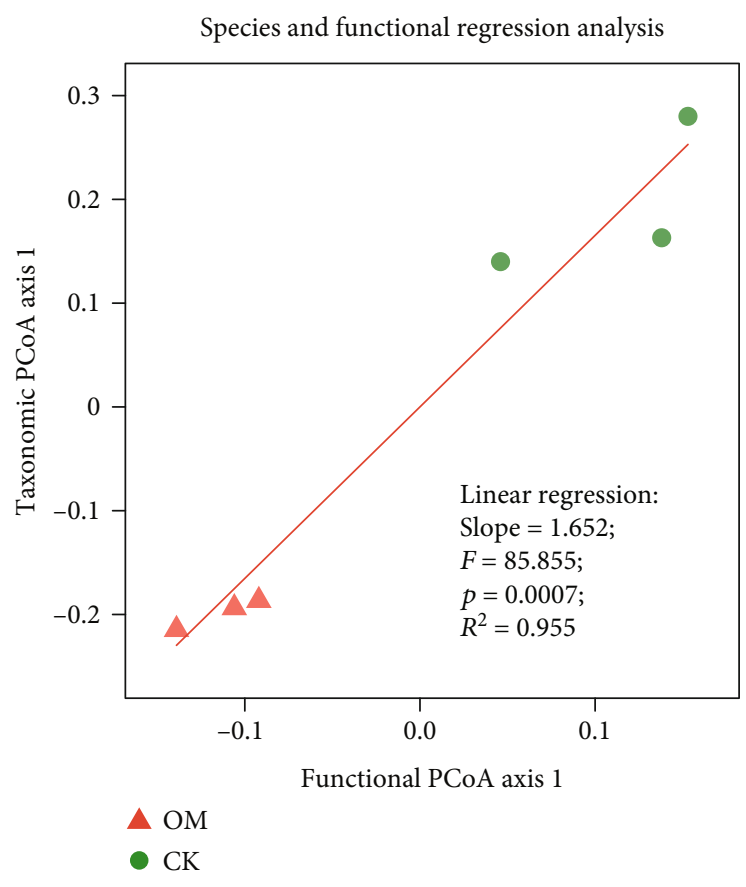

(c)

FiguRE 2: Effects of experimental treatments on the taxonomic (a) and functional (b) composition of soil microbial communities and the relationship between the taxonomic and functional compositions (c). ANOSIM indicates the significance of the difference between groups.

correlated with $\mathrm{pH}, \mathrm{TP}, \mathrm{TN}$, and $\mathrm{OM}$, but negatively correlated with TS (Figure 4).

3.6. Microorganism Function Analysis. According to the aligned results of KEGG, the total functions $(6,49$, and 409 ) at the three levels (L1, L2, and L3) were identified from the microorganisms obtained from two soil samples. The majority of sequences were functionally associated with metabolism (70.24\%-70.64\%), genetic information processing $(8.00 \%-8.41 \%)$, environmental information processing
(7.47\%-7.81\%), cellular processes (6.25\%-6.76\%), human diseases $(4.37 \%-4.41 \%)$, and organismal systems $(2.78 \%-2.78 \%)$ (Figure 1(b)). We also observed differences in seven classified functions at the L2 level through statistical analysis. Application of OM significantly increased the relative abundance of nucleotide metabolism and energy metabolism compared with CK treatment (Figure 3(b)). However, compared with $\mathrm{CK}, \mathrm{OM}$ decreased in seven functional categories, including lipid metabolism, glycan biosynthesis and metabolism, metabolism of cofactors and vitamins, metabolism of other 


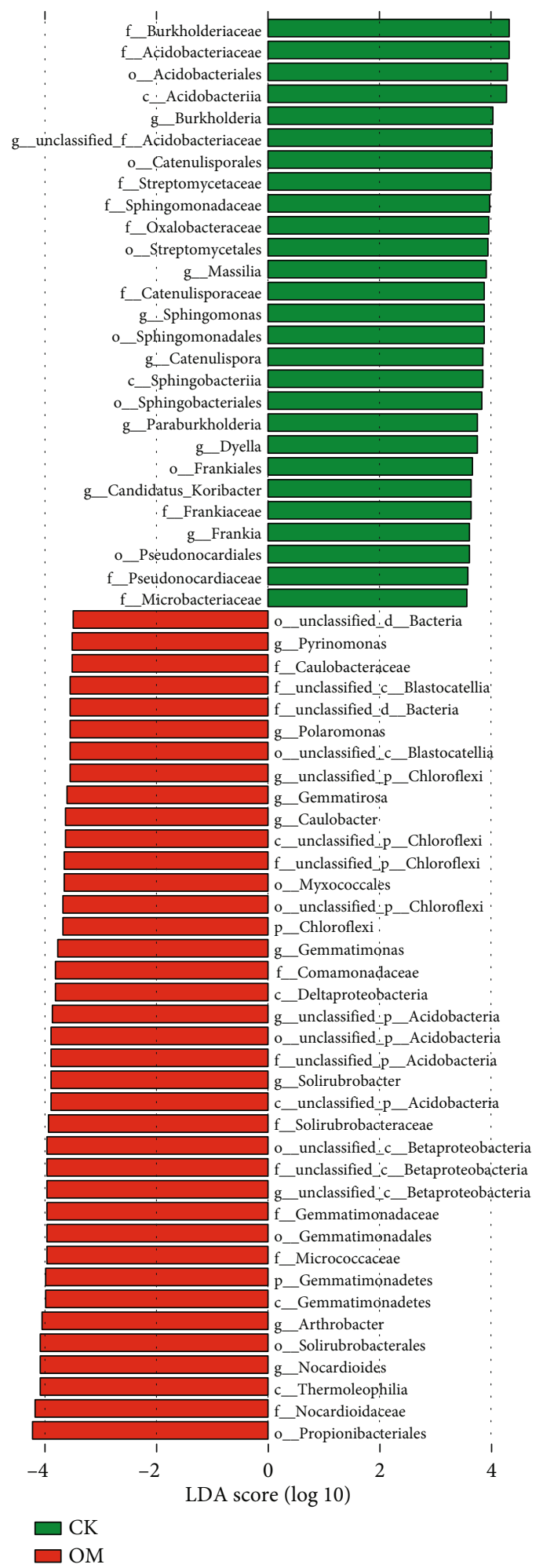

(a)

Figure 3: Continued. 


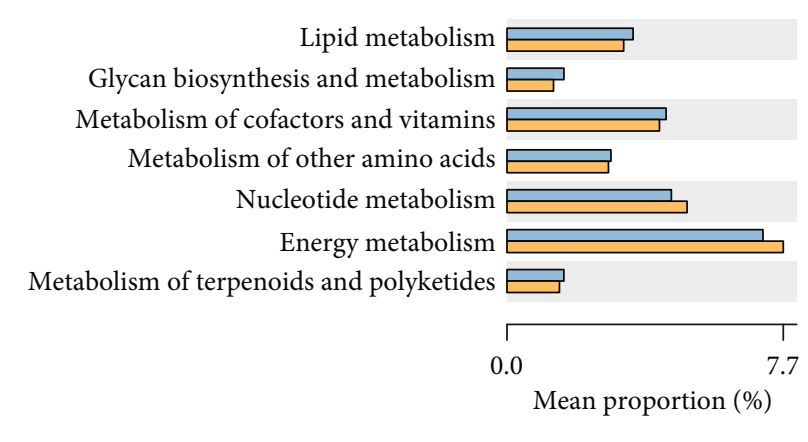

Lipid metabolism

Glycan biosynthesis and metabolism etabolism of cofactors and vitamin Nucleotide metabolism

Energy metabolism

Mean proportion (\%)

95\% confidence intervals

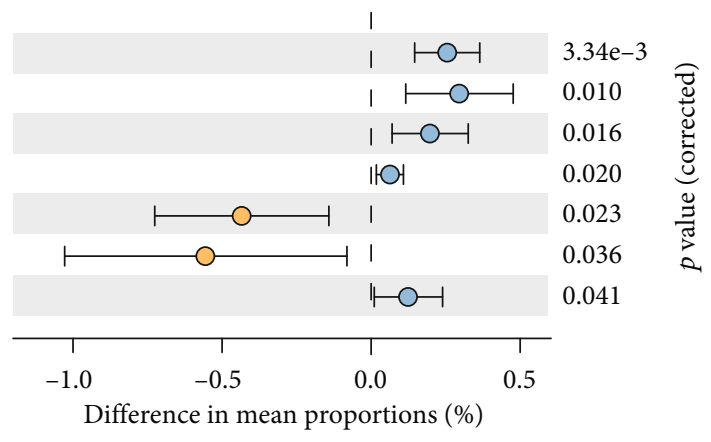

(b)

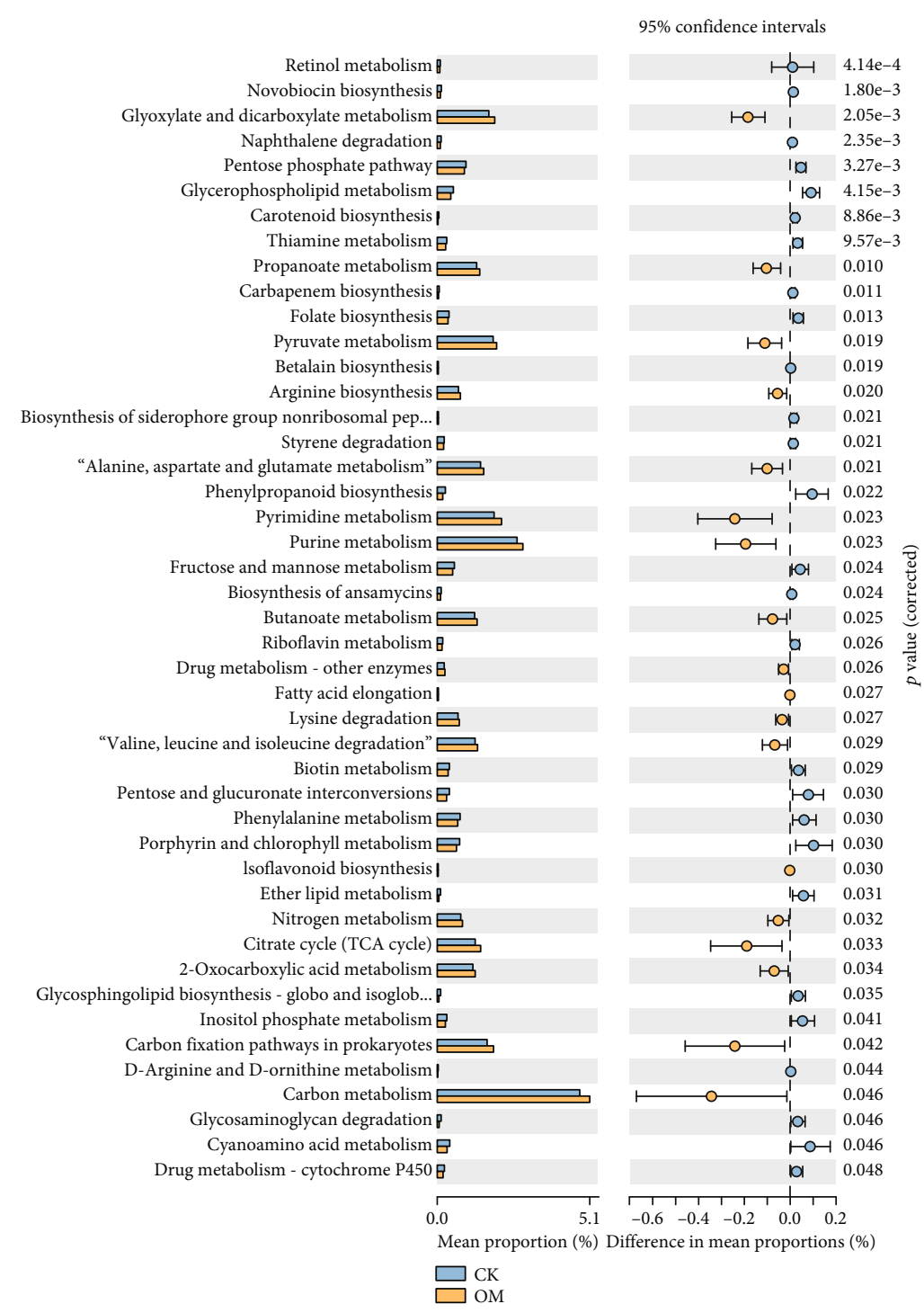

(c)

FIGURE 3: Histograms showing the phylogenetic distribution of the microorganism lineages associated with the two sugarcane fields. Lineages with LDA values higher than 3.5 are displayed (a). Different-colored regions represent different constituents (red: OM, green: CK). Extended error bar plots indicate significantly different predicted functional categories at level 2 (b) and level 3 (c) detected in CK and OM treatments $(p<0.05$, mean proportion, $n=3)$. 


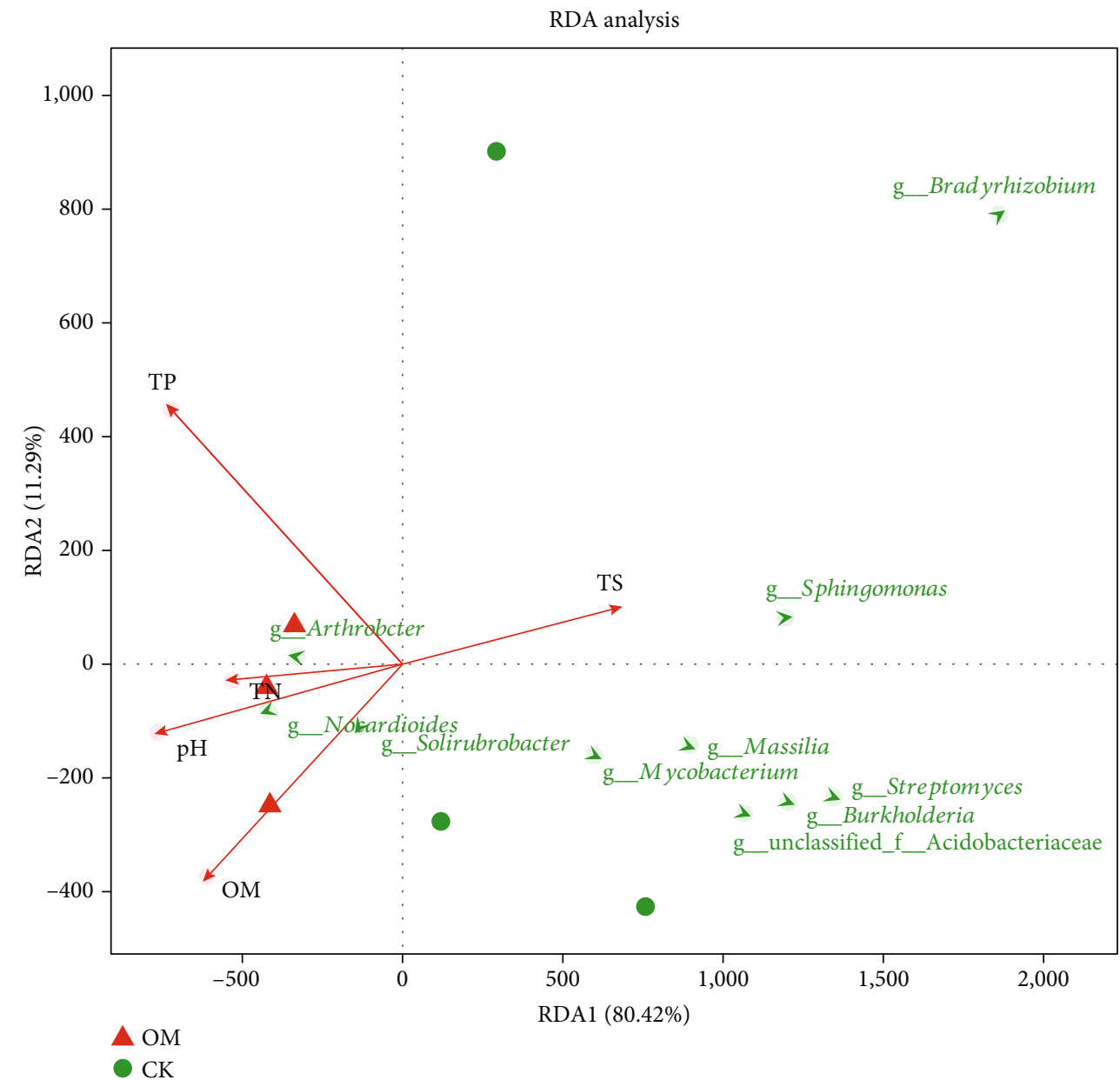

FIgURE 4: Redundancy analysis of soil properties and dominant microorganism genus. Soil property abbreviations: TN: total nitrogen; TP: total phosphorus; TS: total sulfur; OM: organic matter.

amino acids, and metabolism of terpenoids and polyketides (Figure 3(c)).

3.7. Increased Sulfur Metabolism to Biomass. Sulfur metabolism was significantly enriched in OM compared to $\mathrm{CK}$, as displayed by the KEGG results (Figure 3(c)). Plants absorb sulfate through the root system to maintain a normal development. Sulfate is reduced by an assimilation sulfate reduction pathway and assimilated into structural and functional organic sulfides. In this study, we explored the promotion of sugarcane biomass by soil microorganisms based on the assimilation sulfate reduction pathway. The abundance of the three sulfate import genes (cysP, cys $V$, and $c y s W$ ) increased by $0.5 \%, 11.6 \%$, and $0.1 \%$ in OM compared to the $\mathrm{CK}$ group, respectively. Most of the genes in the assimilation sulfate reduction pathway were also more abundant in the $\mathrm{OM}$ data set, such as sulfate adenyitransferase ( $c y s N C, c y s N$, $c y s D$, and sat), adenylyl-sulfate kinase (cysNC, cysC), phosphoadenylyl-sulfate reductase $(c y s H)$, and assimilatory sulfite reductase (sir). Only assimilatory sulfite reductase (cysI, cysJ) showed a decline (Figure 5). The conclusions are consistent with the result of Zhang et al. [34], whose results suggested that the application of organic fertilizer could pro- mote the absorption of soil sulfate by stimulating the growth of soil microorganisms.

\section{Discussion}

Our research explored the impact of organic fertilizer application on soil physiochemical properties, agronomic traits, and microbial composition in the sugarcane cropping system. The results revealed that the application of organic fertilizer improved the sugarcane agronomic traits and yield, a finding that is with previous studies on strawberry [35], rice [36], and watermelon [37]. In addition, the application of organic fertilizers can also increase soil nutrient status and reduce soil acidification in sugarcane planting systems [3840]. Based on the results of our study, we therefore believe that mitigating soil acidification and optimizing the soil nutrient status of sugarcane fields can help improve sugarcane yields.

The $\mathrm{pH}$ value and $\mathrm{N}, \mathrm{P}$, and $\mathrm{S}$ contents of soil are very sensitive to the changes of organic matter and can be used as indicators to evaluate soil quality. Moreover, these soil indicators can influence the composition of soil microorganism communities. Although the overall number of soil 


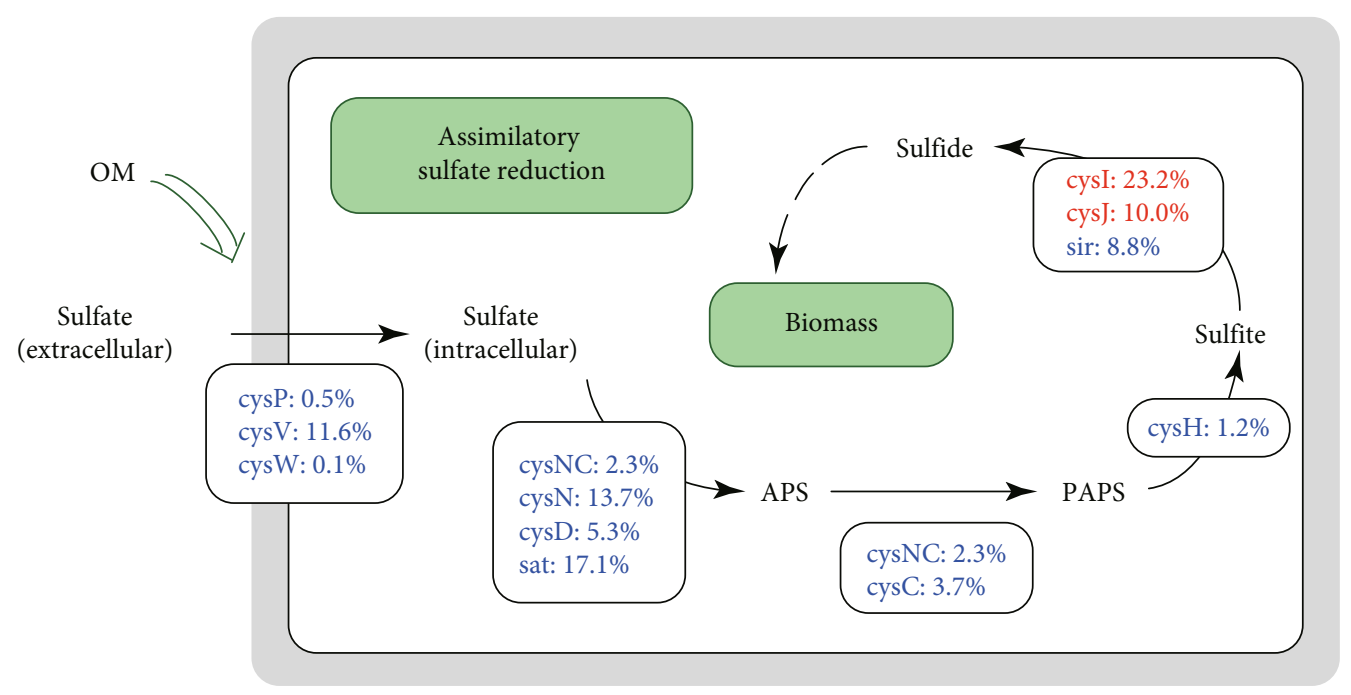

FIGURE 5: The pathway of import and assimilatory sulfate reduction under organic fertilizer. Percentages indicate the relative variation compared with CK. Percentages given in red and blue represent an increase or decrease in the abundance of the genes.

microbial species remained almost the same, the dominant species changed significantly. This finding reflects those of previous studies, in which the application of organic fertilizer changed the characteristics of soil microbial communities [40-42]. The effects of organic fertilizers on soil microorganisms have been widely investigated in various agricultural systems [43-45]. Our RDA analysis revealed that the changes in soil microbial community composition were associated with soil physiochemical properties. In particular, OM treatment has a significant influence on microbial community composition. In the OM treatment, the phyla Acidobacteria, Proteobacteria, Chloroflexi, and Gemmatimonadetes were abundant compared with the CK community. Members associated with Acidobacteria generally accounted for $20 \%$ to $50 \%$ of the total amount of bacteria. Acidobacteria has been reported to have a variety of functions, such as the degradation of plant polymers [46], participation in the iron cycle [47], photosynthesis capability [48], and participation in the carbon cycle [49]. Proteobacteria is a phylum with significant functions in the degradation of biofertilizers [50] as well as in sulfate reduction [51]. Chloroflexi is a kind of photoautotrophic bacteria with the ability to degrade organic matter, and they tend to grow in a nutrient-rich environment [52]. Gemmatimonadetes reproduce by germination, and its members have salt-resistant properties. Results of previous studies have shown that Gemmatimonadetes is positively correlated with soil conductivity [53]. The OM field was also characterized by Pyrinomonas, Solirubrobacter, Arthrobacter, Nocardia, Gemmatimonas, Polaromonas, and Caulobacter, unlike the CK field. Among them, Pyrinomonas belongs to Acidobacteria; Solirubrobacter, Arthrobacter, and Nocardia belong to Actinobacteria; Gemmatimonas belong to Gemmatimonadetes; and Polaromonas and Caulobacter belong to Proteobacteria. These genera were seldom reported in previous studies in fields cultivated with sugarcane. However, the phyla of these genera have also been reported many times in other sugarcane soil studies. Acidobacteria and Actinomycetes are also more common in sugarcane soils treated with nitrogen fertilizer [54, 55]. Proteobacteria significantly increased in bagasse mulching sugarcane soil [14]. In comparison with CK, two functional classes, namely, nucleotide metabolism and energy metabolism, increased significantly in the OM field. In addition, we analyzed the effects of soil microorganisms on sulfur metabolism and found that the sulfate import genes such as cys $P, c y s V$, and $c y s W$, and most of the genes involved in the sulfate reduction pathways, increased in the OM. This finding is consistent with previous studies and suggests that the application of organic fertilizer can promote the conversion process of extracellular sulfate to biomass in sulfur metabolism $[34,56]$.

In summary, we assess the effects of organic fertilizer on the microbial community of sugarcane soil using a metagenomic approach and found that there was a close relationship between the parameters of sugarcane, soil nutrients, and soil microorganisms. Our study provides insights into reforming cropping soil and increasing the yield of sugarcane and other plants in the future.

\section{Data Availability}

The sequencing reads were deposited in the Sequence Reads Archive database of the National Center for Biotechnology (accession no. SRA: SRP280068).

\section{Conflicts of Interest}

The authors declare no conflicts of interest.

\section{Acknowledgments}

We want to praise the donor agencies of China for supporting this project. This research was funded by the Modern Agricultural Industry Technology System of China (CARS170208), the Natural Science Foundation of Fujian Province (2017J01456), and the Special Foundation for Scientific and 
Technological Innovation of Fujian Agriculture and Forestry University (CXZX2016172 and CXZX2017349).

\section{References}

[1] C. A. C. Crusciol, M. de Campos, J. M. Martello et al., "Organomineral fertilizer as source of $\mathrm{P}$ and $\mathrm{K}$ for sugarcane," Scientific Reports, vol. 10, no. 1, article 5398, 2020.

[2] F. Khalil, X. Yueyu, X. Naiyan et al., "Genome characterization of sugarcane yellow leaf virus with special reference to RNAi based molecular breeding," Microbial Pathogenesis, vol. 120, pp. 187-197, 2018.

[3] J. Zhang, X. Zhang, H. Tang et al., "Allele-defined genome of the autopolyploid sugarcane Saccharum spontaneum L," Nature Genetics, vol. 50, no. 11, pp. 1565-1573, 2018.

[4] W. Lin, M. Lin, H. Zhou, H. Wu, Z. Li, and W. Lin, "The effects of chemical and organic fertilizer usage on rhizosphere soil in tea orchards," PLoS One, vol. 14, no. 5, article e0217018, 2019.

[5] J. M. Levine, "Species diversity and biological invasions: relating local process to community pattern," Science, vol. 288, no. 5467, pp. 852-854, 2000.

[6] Y. Yu, M. Wu, E. Petropoulos et al., "Responses of paddy soil bacterial community assembly to different long-term fertilizations in Southeast China," Science of the Total Environment, vol. 656, pp. 625-633, 2019.

[7] M.-g. Xu, H.-j. Tang, X.-y. Yang, and S.-w. Zhou, "Best soil managements from long-term field experiments for sustainable agriculture," Journal of Integrative Agriculture, vol. 14, no. 12, pp. 2401-2404, 2015.

[8] N. Fierer, "Embracing the unknown: disentangling the complexities of the soil microbiome," Nature Reviews Microbiology, vol. 15, no. 10, pp. 579-590, 2017.

[9] J. John, V. Siva, R. Kumari, A. Arya, and A. Kumar, "Unveiling cultivable and uncultivable halophilic bacteria inhabiting Marakkanam saltpan, India and their potential for biotechnological applications," Geomicrobiology Journal, vol. 37, no. 8, pp. 691-701, 2020.

[10] J. Handelsman, M. R. Rondon, S. F. Brady, J. Clardy, and R. M. Goodman, "Molecular biological access to the chemistry of unknown soil microbes: a new frontier for natural products," Chemistry \& Biology, vol. 5, no. 10, pp. R245-R249, 1998.

[11] J. A. Garrido-Cardenas and F. Manzano-Agugliaro, "The metagenomics worldwide research," Current Genetics, vol. 63, no. 5, pp. 819-829, 2017.

[12] A. Madhavan, R. Sindhu, B. Parameswaran, R. K. Sukumaran, and A. Pandey, "Metagenome analysis: a powerful tool for enzyme bioprospecting," Applied Biochemistry and Biotechnology, vol. 183, no. 2, pp. 636-651, 2017.

[13] K. R. Steingart, M. Henry, V. Ng et al., "Fluorescence versus conventional sputum smear microscopy for tuberculosis: a systematic review," The Lancet Infectious Diseases, vol. 6, no. 9, pp. 570-581, 2006.

[14] T. Miura, A. Niswati, I. G. Swibawa et al., "Shifts in the composition and potential functions of soil microbial communities responding to a no-tillage practice and bagasse mulching on a sugarcane plantation," Biology and Fertility of Soils, vol. 52, no. 3, pp. 307-322, 2016.

[15] K. Hamonts, P. Trivedi, J. Grinyer et al., "Yellow canopy syndrome in sugarcane is associated with shifts in the rhizosphere soil metagenome but not with overall soil microbial function," Soil Biology and Biochemistry, vol. 125, pp. 275-285, 2018.
[16] L. P. P. Braga, C. A. Yoshiura, C. D. Borges et al., "Disentangling the influence of earthworms in sugarcane rhizosphere," Scientific Reports, vol. 6, no. 1, article 38923, 2016.

[17] J. Luo, Y.-B. Pan, L. Xu, M. P. Grisham, H. Zhang, and Y. Que, "Rational regional distribution of sugarcane cultivars in China," Scientific Reports, vol. 5, no. 1, article 15721, 2015.

[18] W. Lin, L. Wu, S. Lin et al., "Metaproteomic analysis of ratoon sugarcane rhizospheric soil," BMC Microbiology, vol. 13, no. 1, p. 135, 2013.

[19] Z. Zuoping, M. Duan, Y. Sha et al., "Effects of different fertilizations on fruit quality, yield and soil fertility in field-grown kiwifruit orchard," International Journal of Agricultural and Biological Engineering, vol. 10, no. 2, pp. 163-172, 2017.

[20] Z. Ou Yang, X. Mei, F. Gao, Y. Li, and J. Guo, "Effect of different nitrogen fertilizer types and application measures on temporal and spatial variation of soil nitrate-nitrogen at cucumber field," Journal of Environmental Protection, vol. 4, no. 1, pp. 129-135, 2013.

[21] Y. Lei, H. Yong-sheng, Z. Yong, and Z. Qiang, "Inversion of soil organic matter content using hyperspectral data based on continuous wavelet transformation," Guang Pu Xue Yu Guang Pu Fen Xi = Guang Pu, vol. 36, pp. 1428-1433, 2016.

[22] H. Xi, J. Shen, Z. Qu et al., "Effects of long-term cotton continuous cropping on soil microbiome," Scientific Reports, vol. 9, no. 1, article 18297, 2019.

[23] M. Pansu and J. Gautheyrou, Eds., "Measurement of nonhumic molecules," in Handbook of Soil Analysis, pp. 453496, Springer Berlin Heidelberg, Berlin, Heidelberg, 2006.

[24] D. Li, C.-M. Liu, R. Luo, K. Sadakane, and T.-W. Lam, "MEGAHIT: an ultra-fast single-node solution for large and complex metagenomics assembly via succinct de Bruijn graph," Bioinformatics, vol. 31, no. 10, pp. 1674-1676, 2015.

[25] H. Noguchi, J. Park, and T. Takagi, "MetaGene: prokaryotic gene finding from environmental genome shotgun sequences," Nucleic Acids Research, vol. 34, no. 19, pp. 5623-5630, 2006.

[26] L. Fu, B. Niu, Z. Zhu, S. Wu, and W. Li, "CD-HIT: accelerated for clustering the next-generation sequencing data," Bioinformatics, vol. 28, no. 23, pp. 3150-3152, 2012.

[27] R. Li, Y. Li, K. Kristiansen, and J. Wang, "SOAP: short oligonucleotide alignment program," Bioinformatics, vol. 24, no. 5, pp. 713-714, 2008.

[28] S. F. Altschul, T. L. Madden, A. A. Schäffer et al., "Gapped BLAST and PSI-BLAST: a new generation of protein database search programs," Nucleic Acids Research, vol. 25, no. 17, pp. 3389-3402, 1997.

[29] E. W. Sayers, J. Beck, J. R. Brister et al., "Database resources of the National Center for Biotechnology Information," Nucleic Acids Research, vol. 48, no. D1, pp. D9-16, 2020.

[30] M. Kanehisa, "KEGG: Kyoto Encyclopedia of Genes and Genomes," Nucleic Acids Research, vol. 28, no. 1, pp. 27-30, 2000.

[31] C. Xie, X. Mao, J. Huang et al., "KOBAS 2.0: a web server for annotation and identification of enriched pathways and diseases," Nucleic Acids Research, vol. 39, Supplement 2, pp. W316-W322, 2011.

[32] M. Krzywinski, J. Schein, I. Birol et al., "Circos: an information aesthetic for comparative genomics," Genome Research, vol. 19, no. 9, pp. 1639-1645, 2009.

[33] N. Segata, J. Izard, L. Waldron et al., "Metagenomic biomarker discovery and explanation," Genome Biology, vol. 12, no. 6, article R60, 2011. 
[34] X. Zhang, E. R. Johnston, L. Li, K. T. Konstantinidis, and X. Han, "Experimental warming reveals positive feedbacks to climate change in the Eurasian steppe," The ISME Journal, vol. 11, no. 4, pp. 885-895, 2017.

[35] B. Pokhrel, K. H. Laursen, and K. K. Petersen, "Yield, quality, and nutrient concentrations of strawberry ( Fragaria $\times$ Ananassa Duch. Cv. "Sonata") grown with different organic fertilizer strategies," Journal of Agricultural and Food Chemistry, vol. 63, no. 23, pp. 5578-5586, 2015.

[36] S. Yang, Y. Xiao, and J. Xu, “Organic fertilizer application increases the soil respiration and net ecosystem carbon dioxide absorption of paddy fields under water-saving irrigation," Environmental Science and Pollution Research, vol. 25, no. 10, pp. 9958-9968, 2018.

[37] S. P. Du, Z. M. Ma, and L. Xue, "Effects of different kinds of organic fertilizer on fruit yield, quality and nutrient uptake of watermelon in gravel-mulched field," Ying Yong Sheng Tai Xue Bao = The Journal of Applied Ecology, vol. 30, no. 4, pp. 1269-1277, 2019.

[38] Y. Geng, G. Cao, L. Wang, and S. Wang, "Effects of equal chemical fertilizer substitutions with organic manure on yield, dry matter, and nitrogen uptake of spring maize and soil nitrogen distribution," PLoS One, vol. 14, no. 7, article e0219512, 2019.

[39] S.-Q. Jiang, Y.-N. Yu, R.-W. Gao et al., "High-throughput absolute quantification sequencing reveals the effect of different fertilizer applications on bacterial community in a tomato cultivated coastal saline soil," Science of the Total Environment, vol. 687, pp. 601-609, 2019.

[40] L. Ye, X. Zhao, E. Bao, J. Li, Z. Zou, and K. Cao, "Bio-organic fertilizer with reduced rates of chemical fertilization improves soil fertility and enhances tomato yield and quality," Scientific Reports, vol. 10, no. 1, p. 177, 2020.

[41] Q.-L. Chen, X.-L. An, B.-X. Zheng, Y.-B. Ma, and J.-Q. Su, "Long-term organic fertilization increased antibiotic resistome in phyllosphere of maize," Science of the Total Environment, vol. 645, pp. 1230-1237, 2018.

[42] J. Wang, C. Xue, Y. Song, L. Wang, Q. Huang, and Q. Shen, "Wheat and rice growth stages and fertilization regimes alter soil bacterial community structure, but not diversity," Frontiers in Microbiology, vol. 7, 2016.

[43] Y. Sun, T. Qiu, M. Gao, M. Shi, H. Zhang, and X. Wang, "Inorganic and organic fertilizers application enhanced antibiotic resistome in greenhouse soils growing vegetables," Ecotoxicology and Environmental Safety, vol. 179, pp. 24-30, 2019.

[44] L. Wang, J. Li, F. Yang et al., "Application of bioorganic fertilizer significantly increased apple yields and shaped bacterial community structure in orchard soil," Microbial Ecology, vol. 73, no. 2, pp. 404-416, 2017.

[45] J. Zhao, J. Liu, H. Liang et al., "Manipulation of the rhizosphere microbial community through application of a new bioorganic fertilizer improves watermelon quality and health," PLoS One, vol. 13, no. 2, article e0192967, 2018.

[46] T. A. Pankratov, L. A. Kirsanova, E. N. Kaparullina, V. V. Kevbrin, and S. N. Dedysh, "Telmatobacter bradus gen. nov., sp. nov., a cellulolytic facultative anaerobe from subdivision 1 of the Acidobacteria, and emended description of Acidobacterium capsulatum Kishimoto et al. 1991," International Journal of Systematic and Evolutionary Microbiology, vol. 62, no. 2, pp. 430-437, 2012.

[47] S. Lu, S. Gischkat, M. Reiche, D. M. Akob, K. B. Hallberg, and K. Küsel, "Ecophysiology of Fe-cycling bacteria in acidic sedi- ments," Applied and Environmental Microbiology, vol. 76, no. 24, pp. 8174-8183, 2010.

[48] D. A. Bryant, A. M. G. Costas, J. A. Maresca et al., "Candidatus Chloracidobacterium thermophilum: an aerobic phototrophic Acidobacterium," Science, vol. 317, no. 5837, pp. 523-526, 2007.

[49] T. A. Pankratov, Y. M. Serkebaeva, I. S. Kulichevskaya, W. Liesack, and S. N. Dedysh, "Substrate-induced growth and isolation of Acidobacteria from acidic Sphagnum peat," The ISME Journal, vol. 2, no. 5, pp. 551-560, 2008.

[50] C. Suarez, S. Ratering, I. Kramer, and S. Schnell, "Cellvibrio diazotrophicus sp. nov., a nitrogen-fixing bacteria isolated from the rhizosphere of salt meadow plants and emended description of the genus Cellvibrio," International Journal of Systematic and Evolutionary Microbiology, vol. 64, Part 2, pp. 481-486, 2014.

[51] Y. Guan, T. Hikmawan, A. Antunes, D. Ngugi, and U. Stingl, "Diversity of methanogens and sulfate-reducing bacteria in the interfaces of five deep-sea anoxic brines of the Red Sea," Research in Microbiology, vol. 166, no. 9, pp. 688-699, 2015.

[52] L. M. C. Daniel, E. Pozzi, E. Foresti, and F. A. Chinalia, "Removal of ammonium via simultaneous nitrification-denitrification nitrite-shortcut in a single packed-bed batch reactor," Bioresource Technology, vol. 100, no. 3, pp. 1100-1107, 2009.

[53] J. Gao, Y. Luo, Y. Wei et al., "Effect of aridity and dune type on rhizosphere soil bacterial communities of Caragana microphylla in desert regions of northern China," PLoS One, vol. 14, no. 10, article e0224195, 2019.

[54] J. E. L. Antunes, M. C. C. P. Lyra, F. J. Ollero et al., "Diversity of plant growth-promoting bacteria associated with sugarcane," Genetics and Molecular Research, vol. 16, no. 2, 2017.

[55] G. Pisa, G. S. Magnani, H. Weber et al., "Diversity of $16 \mathrm{~S}$ RRNA genes from bacteria of sugarcane rhizosphere soil," Brazilian Journal of Medical and Biological Research, vol. 44, no. 12, pp. 1215-1221, 2011.

[56] M. A. Tabatabai, J. W. B. Stewart, and J. J. Schoenau, "Sulfur in agriculture,” Soil Science, vol. 145, no. 6, pp. 462-463, 1988. 